\title{
Treating Percutaneous Coronary Intervention-Related Myocardial Injury with Metformin
}

\author{
John W. Calvert \\ Division of Cardiothoracic Surgery, Department of Surgery, Carlyle Fraser Heart Center, Emory University \\ School of Medicine, Atlanta, Ga., USA
}

Coronary artery disease (CAD) resulting from the build-up of plaque in the arteries of the heart remains a leading cause of morbidity and mortality throughout the world. In clinical practices, percutaneous coronary intervention (PCI) has become the standard, nonsurgical revascularization procedure for opening blocked arteries in patients with CAD [1]. Substantial advances in the technology behind PCI coupled with its routine use have made this procedure relatively safe. As such, PCI plays a central role in the management of patients with both stable and unstable CAD. However, despite the purported safety of PCI, $5-30 \%$ of patients undergoing this procedure experience postprocedure or periprocedural myocardial injury (PMI) $[2,3]$. At the upper end of this range, the occurrence of myocardial events is similar to the annual rate of major spontaneous myocardial infarction [4], making PMI a serious clinical complication. PMI generally is a result of procedural complications such as distal embolization, side-branch occlusion, coronary dissection, or disruption of collateral blood flow [1]. The occurrence of these complications is associated with risk factors related to the individual patient or the type of coronary lesion [2, 4]. For instance, patient-related factors such as advanced age, diabetes, renal failure, multivessel disease, and left ventricular dysfunction are important determinants of clinical outcomes following PCI [5]. Importantly, PMI also occurs silently after an uneventful
PCI [1], which underscores the need to monitor patients post-PCI and to develop therapeutic strategies to combat PMI.

The assessment of circulating biomarkers such as troponin I or T and creatine kinase-MB (CK-MB) following PCI has become an important clinical tool for the identification of patients at risk for the development of PMI [1, $3,4]$. For example, a rise in circulating CK-MB levels to 5 times the upper limit of normal likely represents a substantial myocardial infarction associated with PMI [4]. In terms of treatment, aspirin [6], clopidogrel [7], and statins [8] have been shown to reduce the incidence of PMI when administered to patients before PCI. In the current issue of Cardiology, Li et al. [9] demonstrate that metformin also has beneficial effects in reducing the incidence of PMI following PCI. In this prospective, open, randomized clinical study, the authors enrolled 152 metabolic syndrome patients scheduled for elective coronary intervention. Importantly, these patients did not have a prior history of metformin treatment. Starting 1 week before the PCI, the patients were randomized into a placebo $(\mathrm{n}=76)$ and a metformin (250 $\mathrm{mg}$ t.i.d.) treatment group $(n=76)$. To evaluate the incidence and severity of PMI, $\mathrm{CK}-\mathrm{MB}$ and troponin I levels were measured at baseline and then at 8 and $24 \mathrm{~h}$ after the procedure. Clinical outcomes were also monitored for 1 year. Metformin pretreatment was found to reduce post-PCI elevations in

\section{KARGER}

E-Mail karger@karger.com

www.karger.com/crd
(C) 2013 S. Karger AG, Basel

0008-6312/13/1272-0130\$38.00/0
John W. Calvert, PhD

Division of Cardiothoracic Surgery, Department of Surgery Carlyle Fraser Heart Center, Emory University School of Medicine 380 Northyards Boulevard, Suite B, Atlanta, GA 30313 (USA)

E-Mail jcalver@emory.edu 
both CK-MB and troponin I. Importantly, during the 1-year follow-up, patients pretreated with metformin experienced lower incidences of all-cause deaths, PMI-related myocardial infarction, hospitalization, and ischemia-driven target lesion revascularizations.

Metformin is one of the most commonly prescribed antihyperglycemic agents for the treatment of type 2 diabetes [10]. Its major effects in terms of blood glucose are mediated through a reduction in hepatic glucose output and an increase in insulin-dependent peripheral glucose utilization [11]. In addition, metformin has cardioprotective effects that are not limited to its ability to lower blood glucose, as evidenced by the findings that treatment with metformin decreases injury associated with acute myocardial infarction and ischemic-induced heart failure [12, 13]. As such, the cardioprotective effects of Li et al. [9] support the emerging concept that metformin is a viable treatment option for myocardial ischemia. Although the exact cardioprotective mechanisms of metformin are currently not known, there is evidence that metformin protects the myocardium via the activation of AMP-activated protein kinase (AMPK), a protein kinase that is activated in response to alterations in cellular energy levels $[10,12$, 13]. Cardiac AMPK activity increases in response to a wide array of stimuli, including ischemia [14], and for the most part, the evidence indicates that activation of AMPK serves a cardioprotective role $[12,15]$. With regard to downstream signaling events, AMPK activation has been shown to increase the activity of endothelial nitric oxide synthase (eNOS), resulting in an increase in the bioavailability of nitric oxide (NO) [12]. NO has been extensively studied in the setting of myocardial ischemia-reperfusion injury. Previous studies have clearly demonstrated that the deficiency of eNOS exacerbates myocardial ischemiareperfusion injury, whereas the overexpression of eNOS, the administration of NO donors, and inhaled NO gas therapy all significantly protect the myocardium [16]. In terms of its cytoprotective mechanisms, NO possesses a number of physiological properties, such as vasodilation, inhibition of oxidative stress, platelet aggregation, leukocyte chemotaxis, and apoptosis, which make it a potent cardioprotective-signaling molecule [17]. Although Li et al. [9] did not evaluate the mechanism by which metformin provided protection, the activation of an AMPKeNOS-NO signaling cascade could certainly account for the observed effects.

In summary, Li et al. [9] provide new insights into the clinical use of metformin with the observation that it reduces the incidence and severity of PMI following PCI. Moreover, the finding that metformin provided these beneficial effects without inducing lactic acidosis supports the emerging concept that metformin treatment does not need to be discontinued prior to PCI. This is an important concept given that the discontinued use of metformin may lead to deleterious effects on glycemic control and may increase the cardiovascular risk, which in turn can increase the risk of complications during PCI. This is especially relevant to patients with metabolic syndrome who already have lesions that make them more susceptible to develop PMI. The findings of the study also reinforce the already strong case for the use of pharmacological agents as a pretreatment strategy to decrease PCIinduced myocardial injury. Finally, the authors' findings open the door for larger-scale clinical trials to investigate the effects of metformin treatment on late outcomes in patients undergoing elective PCI.

\section{Acknowledgements}

This study was supported by a grant from the National Institutes of Health's National Heart, Lung, and Blood Institute (NHLBI) (5R01HL098481-04) to J.W.C. This work was also supported by funding from the Carlyle Fraser Heart Center (CFHC) of Emory University Hospital Midtown.

\section{References}

$\nabla_{1}$ Cuculi F, Lim CC, Banning AP: Periprocedural myocardial injury during elective percutaneous coronary intervention: is it important and how can it be prevented? Heart 2010; 96:736-740.

- 2 Herrmann J: Peri-procedural myocardial injury: 2005 update. Eur Heart J 2005;26:24932519.

-3 Califf RM, Abdelmeguid AE, Kuntz RE, Popma JJ, Davidson CJ, Cohen EA, Kleiman NS, Mahaffey KW, Topol EJ, Pepine CJ, Lipicky
RJ, Granger $\mathrm{CB}$, Harrington RA, Tardiff BE, Crenshaw BS, Bauman RP, Zuckerman BD, Chaitman BR, Bittl JA, Ohman EM: Myonecrosis after revascularization procedures. J Am Coll Cardiol 1998;31:241-251.

-4 Prasad A, Herrmann J: Myocardial infarction due to percutaneous coronary intervention. $\mathrm{N}$ Engl J Med 2011;364:453-464.

-5 Blankenship JC, Haldis T, Feit F, Hu T, Kleiman NS, Topol EJ, Lincoff AM: Angiographic adverse events, creatine kinase-MB eleva- tion, and ischemic end points complicating percutaneous coronary intervention (a REPLACE-2 substudy). Am J Cardiol 2006;97: 1591-1596.

-6 Schwartz L, Bourassa MG, Lesperance J, Aldridge HE, Kazim F, Salvatori VA, Henderson M, Bonan R, David PR: Aspirin and dipyridamole in the prevention of restenosis after percutaneous transluminal coronary angioplasty. N Engl J Med 1988;318:17141719.
Treating PCI-Related Myocardial Injury with Metformin
Cardiology 2014;127:130-132 DOI: $10.1159 / 000356875$ 
7 Moore RK, Lowe R, Grayson AD, Morris JL, Perry RA, Stables RH: A study comparing the incidence and predictors of creatine kinase $\mathrm{MB}$ and troponin T release after coronary angioplasty. Does clopidogrel preloading reduce myocardial necrosis following elective percutaneous coronary intervention? Int J Cardiol 2007;116:93-97.

-8 Briguori C, Visconti G, Focaccio A, Golia B, Chieffo A, Castelli A, Mussardo M, Montorfano M, Ricciardelli B, Colombo A: Novel approaches for preventing or limiting events (NAPLES) II trial: impact of a single high loading dose of atorvastatin on periprocedural myocardial infarction. J Am Coll Cardiol 2009;54:2157-2163.

$\square_{9} \mathrm{Li}$ J, Xu J, Zhao X, Sun X, Xu Z, Song S: Protective effect of metformin on myocardial injury in metabolic syndrome patients following percutaneous coronary intervention. Cardiology 2014;127:133-139.
10 Davis BJ, Xie Z, Viollet B, Zou MH: Activation of the AMP-activated kinase by antidiabetes drug metformin stimulates nitric oxide synthesis in vivo by promoting the association of heat shock protein 90 and endothelial nitric oxide synthase. Diabetes 2006;55:496505.

11 Owen MR, Doran E, Halestrap AP: Evidence that metformin exerts its anti-diabetic effects through inhibition of complex 1 of the mitochondrial respiratory chain. Biochem J 2000; 348:607-614.

12 Calvert JW, Gundewar S, Jha S, Greer JJ, Bestermann WH, Tian R, Lefer DJ: Acute metformin therapy confers cardioprotection against myocardial infarction via AMPK-ENOS-mediated signaling. Diabetes 2008;57:696-705.
13 Gundewar S, Calvert JW, Jha S, Toedt-Pingel I, Ji SY, Nunez D, Ramachandran A, AnayaCisneros M, Tian R, Lefer DJ: Activation of AMP-activated protein kinase by metformin improves left ventricular function and survival in heart failure. Circ Res 2009;104:403-411.

14 Zaha VG, Young LH: AMP-activated protein kinase regulation and biological actions in the heart. Circ Res 2012;111:800-814.

15 Russell RR 3rd, Li J, Coven DL, Pypaert M, Zechner C, Palmeri M, Giordano FJ, Mu J, Birnbaum MJ, Young LH: AMP-activated protein kinase mediates ischemic glucose uptake and prevents postischemic cardiac dysfunction, apoptosis, and injury. J Clin Invest 2004;114:495-503.

16 Calvert JW, Lefer DJ: Myocardial protection by nitrite. Cardiovasc Res 2009;83:195-203.

17 Lefer DJ: Myocardial protective actions of nitric oxide donors after myocardial ischemia and reperfusion. New Horiz 1995;3:105-112. 